\title{
Interaction Between Swash Plate Movement And Commutation In Axial Piston Machines*
}

\author{
Florian SCHOEMACKER ${ }^{* *}$ and Hubertus MURRENHOFF ${ }^{* *}$
}

\begin{abstract}
In a variable displacement pump the swash plate has the ability to oscillate because of the excitation of the piston pressure forces. The odd number of pistons and the alternating piston pressure produce a periodically changing torque load. The resulting swash plate movement alters the piston stroke and therefore interacts with the piston pressure gradient. In this study a simulation model of the dynamics of a variable displacement pump is developed and the interaction between the swash plate movement and the commutation is investigated. The torque load influence of different valve plate designs is analyzed and presented in this paper.
\end{abstract}

Keywords: Axial Piston Pump, Swash Plate Torque Load, Swash Plate Oscillations, Valve Plate Design, Commutation

\section{Introduction}

The system "hydraulic variable displacement pump" consists of mainly two components. One is the pump itself with the cylinder block, pistons, valve plate and swash plate. The other part is the pump controller including the control valve and control actuators. The design of the pump controller depends on the function of the pump system, for example pressure compensation or flow control. In order to change the displacement volume, the pump controller acts on the swash plate via the control piston. During steady-state operation, the resulting force of the control piston is in equilibrium with the torque load of the piston pressure forces acting on the swash plate. Because of the odd number of pistons and the alternating piston pressure, these forces produce a periodically changing torque. Current research has shown that the torque load results in a movement of the swash plate and a pressure variation in the control actuator.

Achten et $\mathrm{al}^{1}{ }^{1}$. showed that the torque load on the swash plate results in a movement of the swash plate. The study was based upon the floating cup principle, which is an axial piston pump with two cylinder blocks and two swash plates, and includes simulations as well as measurements. The results show that the oscillation of the swash plate angle eventually changes the sinusoidal movement of the pistons at the dead

\footnotetext{
* $\quad$ Manuscript received January 02, 2018

** Institute of Fluid Power Drives and Controls (IFAS) RWTH Aachen

Campus Boulevard 30, 52074 Aachen, Germany

E-mail: Florian.Schoemacker@ifas.rwth-aachen.de
}

centers, which results in a variation of the piston pressure gradient during the commutation between the pressure levels. Furthermore the pump's efficiency is reduced in controlled operation because of additional volume flow in the pump controller. The swash plate oscillations cause a pressure variation in the control actuator and therefore the flow in the pump controller.

Ericson $^{2)}$ has investigated the swash plate oscillation for a conventional swash-plate type axial piston pump. The simulation of the pump model showed a variation of the piston stroke during commutation. Due to the dynamics of the swash plate, the amplitude of the oscillation depends on the pumps rotational speed. Slower speeds result in a higher amplitude because of the low natural frequency of the swash plate. However the pump's output volume flow is only slightly affected by the swash plate oscillations.

For the simulation of the swash plate oscillations a detailed model of the pressure built-up dynamics during commutation as well as a pump controller model is needed. Manring and Johnson $^{3)}$ published a mathematical description of the model for a variable displacement pump. Manring ${ }^{4)}$ also studied the forces acting on the swash plate and their variation due to the odd number of pistons. For the simulation of a control operated pump, Mandal et $\mathrm{al}^{5)}$. developed a model of the pressure compensator for a variable displacement pump. The model was used for designing the pump controller according to the dynamics of the swash plate.

Within a research project at IFAS, pump controller losses were investigated, showing an efficiency reduction of pumps 
in closed-loop control $^{6}$. The power loss is almost constant for all swash plate angles and differs with the pressure level.

For their simulations all authors used valve plate geometries with silencing grooves. In this study the impact of the valve plate design on the torque load and therefore on the movement of the swash plate is investigated. The thesis is that the valve plate design has a strong impact on the torque load which then causes the swash plate movement. As stated before, the swash plate movement interacts with the commutation. In order to investigate the effect of the valve plate design on this interaction, different valve plate designs using silencing grooves and bores are simulated. Therefore a new simulation model with the ability to calculate pump dynamics including the swash plate torque load and oscillations has been developed.

\section{Nomenclature}

\begin{tabular}{|c|c|c|}
\hline$s_{i}$ & 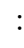 & Piston stroke \\
\hline$v_{i}$ & : & Piston velocity \\
\hline$a_{i}$ & 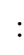 & Piston acceleration \\
\hline$R$ & : & Radius of piston \\
\hline$h$ & : & Lever arm \\
\hline$V_{i}\left(\varphi_{i}\right)$ & : & Piston displacement chamber volume \\
\hline$A_{i}\left(\varphi_{i}\right)$ & : & Opening area \\
\hline$A_{\text {Piston }}$ & : & Piston area \\
\hline$A_{\mathrm{C}}$ & : & Control actuator area \\
\hline$Q_{i}$ & : & Flow rate of one piston \\
\hline$p_{\mathrm{HP}}$ & ${ }^{\circ}$ & High pressure \\
\hline$p_{i}\left(\varphi_{i}\right)$ & : & Piston pressure \\
\hline$p_{\mathrm{A}}$ & : & Actuator pressure \\
\hline$E_{\text {Oil }}$ & : & Bulk modulus \\
\hline$\alpha$ & : & Area ratio \\
\hline$\alpha_{\mathrm{D}}$ & : & Flow rate coefficient \\
\hline$\beta$ & : & Swash plate angle \\
\hline$\varphi$ & : & Rotational angle \\
\hline$M_{\text {Eigen }, i}$ & : & Torque load of piston \\
\hline$J_{\mathrm{SP}}$ & : & Swash plate's moment of inertia \\
\hline$d_{\mathrm{SP}}$ & & Swash plate damping \\
\hline$c_{\mathrm{SP}}$ & : & Spring ratio \\
\hline \multicolumn{3}{|c|}{ Subscript } \\
\hline$i$ & (8) & Piston number \\
\hline$S P$ & : & Swash Plate \\
\hline
\end{tabular}

\section{Geometry}

For the analysis a swash plate-type axial piston pump has been chosen as a variable displacement controlled pump. The pump controller type is a pressure compensator which adjusts the output flow according to the hydraulic system's need in order to hold constant pressure. The pump's geometric data is derived from a fictional axial piston pump with a power output of about $30 \mathrm{~kW}$. Fig. 1 shows the assembly of the pump system and a sketch of the hydraulic system used for displacement control. Forces acting on the swash plate are displayed as well.

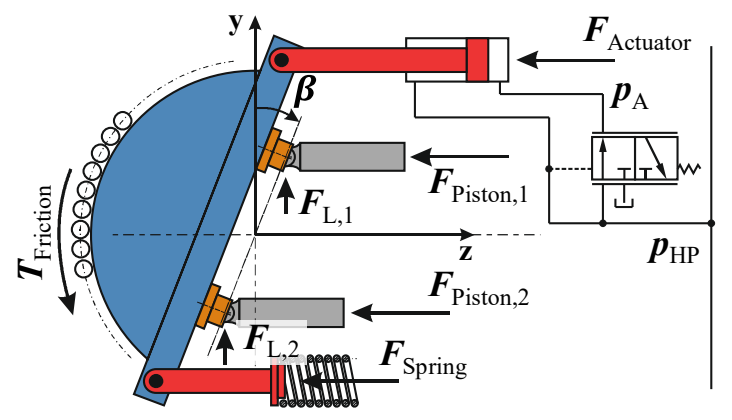

Fig.1 Pump system with pressure compensator

The piston pressure forces act on the swash plate creating a periodically changing torque load. A spring provides the swash plate with an initial torque load for swiveling out if the pump is in unpressurised condition. The torque load on the swash plate is balanced by the control actuator's force. The actuator is supplied by the pump controller which changes the swash plate angle in control operation.

The pump model consists of the piston assembly's mathematical description and its commutation to the high and low pressure kidney. The mathematical calculation is based upon a Cartesian coordinate system which is shown on Fig. 1 and Fig. 2. The valve plates in Fig. 2 are displayed with their contact surface for the cylinder block.
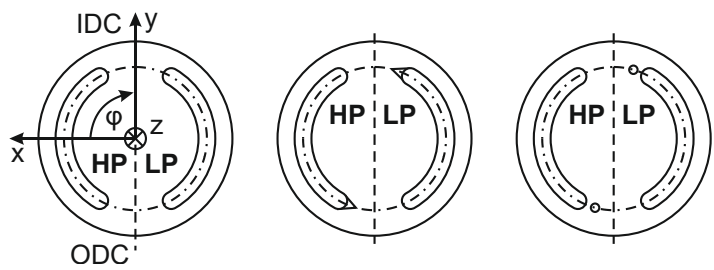

Fig.2 Different valve plate designs

(VP 1: no commutation element, VP 2: grooves, VP 3: bores)

The used definition of the coordinate system and the rotational angle $\varphi$ is chosen to be able to calculate using the vector product. Also this definition has the outcome that the zero angle for the rotational angle $\varphi$ lies within the high pressure kidney. As stated before the design of the valve plate is taken into account for the study. The designs of the valve plates used for the simulation are shown in Fig. 2.

In order to compare the results of the calculation the opening area of the commutation between the piston bore and 
the valve plate is the same for the grooves and the bores. The starting angle of commutation is the same and the finally opened area has the same value. The different graphs for the valve plates are shown in Fig. 3.

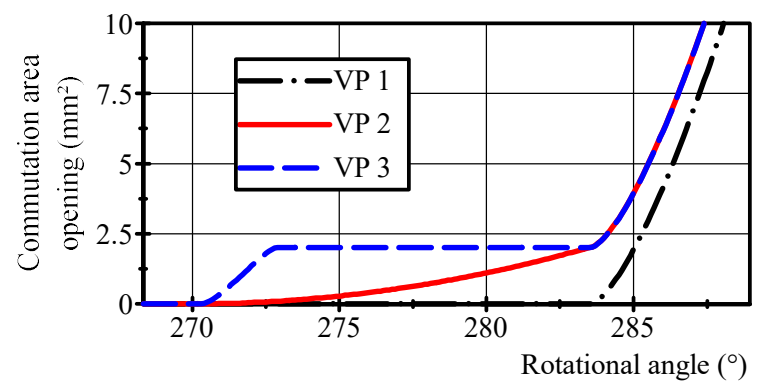

Fig. 3 Commutation area opening for VP 1, VP 2 and VP 3

Valve plate 1 does not have any commutation element. Therefore the gradient of the opening area depends solely on the radius and the width of the kidneys. The gradient is almost constant. Especially at the beginning of the commutation a high backward volume flow from the high pressure port into the piston's displacement chamber occurs. Therefore the pump's output flow pulsates quite strongly.

The silencing groove of VP 2 provides a quadratic rising of the opening area. Therefore the area increases gradually. In hydraulic terms this means that the resistance for the backward-flow from the high pressure port into the displacement chamber is quite high at first and decreases afterwards while the pressure difference between piston chamber and high pressure port drops. Eventually an almost constant backward-flow occurs.

Valve plate 3 with the silencing bore offers a quick opening of the entire bore as a commutation area which is held constant until the opening in the cylinder block hits the high pressure port. Therefore the resistance of the commutation is held constant and the backwards volume flow only depends on the remaining pressure difference.

\section{Simulation Model}

For the 1D-simulation the pump and controller components have been modelled. Each individual piston stroke is calculated via the mathematical function containing the rotational angle and the swashplate angle (1). Due to the aforementioned effects, the swash plate angle can no longer be taken as a constant value and leads to further terms in the derivation of the velocity (2) and the acceleration (3).

$$
\begin{aligned}
& s_{i}=R \cdot \tan (\beta) \cdot \sin \left(\varphi_{\mathrm{i}}\right) \\
& v_{i}=\dot{s}_{i}=R \cdot\left[\sin \left(\varphi_{i}\right) \cdot\left(\dot{\beta} \cdot\left(1+\tan ^{2}(\beta)\right)\right)+\right. \\
& \left.\cos \left(\varphi_{i}\right) \cdot(\dot{\varphi} \cdot \tan (\beta))\right]
\end{aligned}
$$

$$
\begin{aligned}
& a_{i}=\ddot{s}_{i}=R \cdot\left[\cos \left(\varphi_{i}\right) \cdot\left(2 \cdot \dot{\beta} \cdot \dot{\varphi} \cdot\left(1+\tan ^{2}(\beta)\right)\right)\right. \\
& \quad+\sin \left(\varphi_{\mathrm{i}}\right) \cdot\left(-\dot{\varphi}^{2} \cdot \tan (\beta)+2 \cdot \dot{\beta}^{2} \cdot \tan (\beta)\right. \\
& \left.\left.\quad\left(1+\tan ^{2}(\beta)\right)+\ddot{\beta} \cdot\left(1+\tan ^{2}(\beta)\right)\right)\right]
\end{aligned}
$$

For each piston the stroke is calculated with $\varphi_{i}=\varphi+i \cdot \Delta \varphi_{i}$.

The connection between the piston chamber and the kidney-shaped openings of the valve plate determines the pressure gradient which is calculated using (4) and (5).

$$
\begin{aligned}
& \dot{p}_{i}\left(\varphi_{i}\right)=\frac{E_{0 \mathrm{il}}}{V_{i}\left(\varphi_{i}\right)} \cdot\left(Q_{i}+A_{\text {piston }} \cdot v_{i}\left(\varphi_{i}\right)\right) \\
& Q_{i}=\alpha_{\mathrm{D}} \cdot A_{i}\left(\varphi_{i}\right) \cdot \sqrt{\frac{2 \cdot\left(p_{\mathrm{HP}}-p_{i}\left(\varphi_{i}\right)\right)}{\rho}}
\end{aligned}
$$

The pressure is a periodically changing function which is displayed in Fig. 4 for all valve plates.

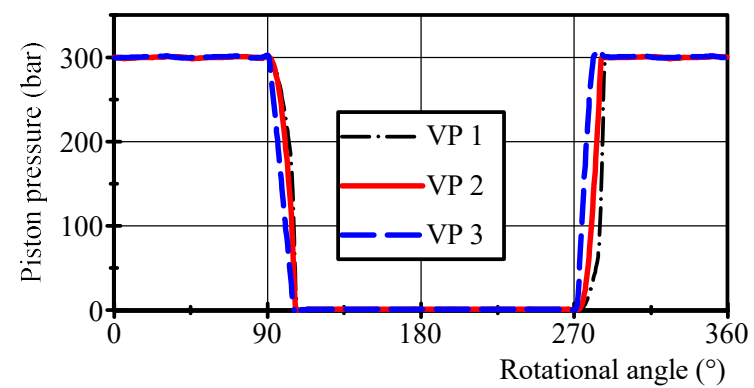

Fig.4 Piston pressure for VP 1, VP 2 and VP 3

Furthermore the resulting piston pressure forces and torque $M_{\mathrm{x}, i}$ on the swash plate are calculated.

$$
M_{\mathrm{x}, i}=R \cdot\left(1+\tan ^{2}(\beta)\right) \cdot A_{\mathrm{piston}} \cdot p_{i\left(\varphi_{i}\right)} \cdot \sin \left(\varphi_{i}\right)
$$

In addition to the piston pressure forces, the spring and actuator forces act on the swash plate. Finally the angle and angular velocity of the swash plate are determined using Euler's laws of motion.

$$
\begin{aligned}
& J_{\mathrm{SP}} \cdot \ddot{\beta}+d_{\mathrm{SP}} \cdot \dot{\beta}+c_{\mathrm{SP}} \cdot \beta=\sum M_{\mathrm{x}, i}+ \\
& h \cdot A_{\mathrm{C}} \cdot\left(\alpha \cdot p_{\mathrm{HP}}-p_{\mathrm{A}}\right)
\end{aligned}
$$

The swash plate angle, its velocity and acceleration are then used as an input for the piston kinematics. For the pump controller a simulation model of a pressure compensator including the spool dynamics is used.

Following boundary conditions are used for the simulation: rotational speed $1500 \mathrm{rpm}$, high pressure 300 bar and a swash plate angle of $15^{\circ}$.

\section{Swash Plate Torque Load}

Utilizing the simulation, a detailed calculation of the forces acting on the swash plate is conducted. The torque load can be used as a result in order to compare different commutation 
designs. Fig. 5 shows the piston pressure and the resulting torque load of the piston on the swash plate $M_{\mathrm{x}, i}$ for one revolution. The torque load is calculated for a mechanically locked swash plate to show the initial torque load. The graphs are displayed for the valve plate with the grooves and the bores.
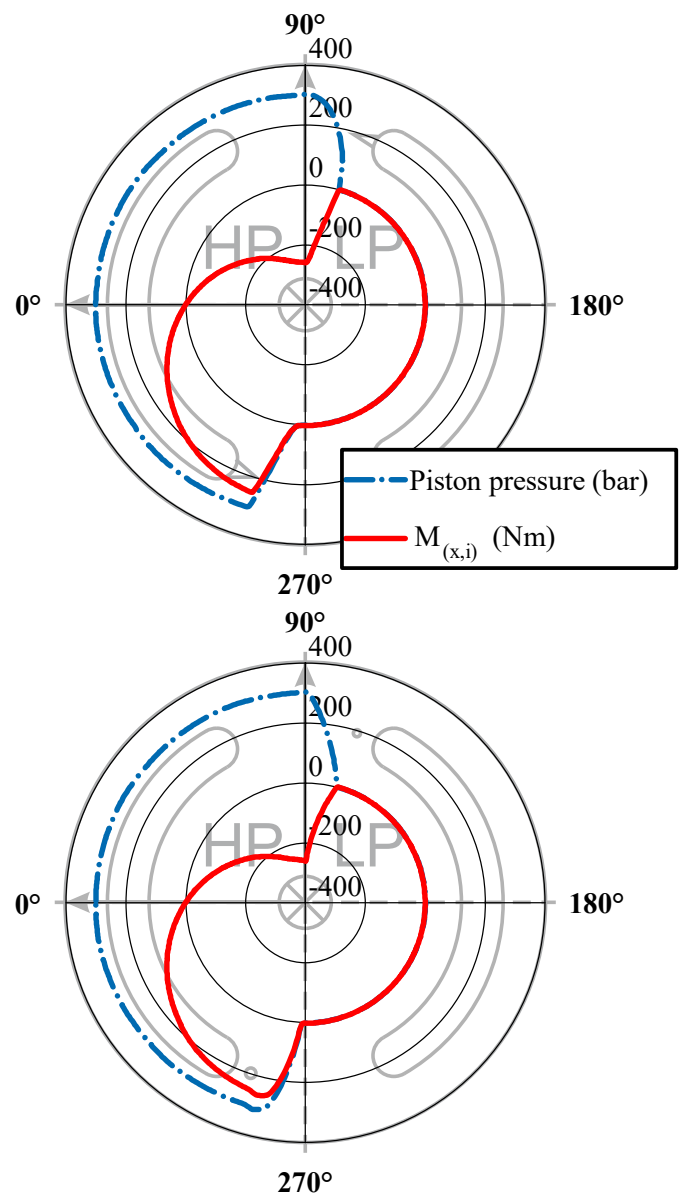

Fig.5 Piston pressure and torque load of one piston (above: VP 2, bottom: VP 3)

As stated in (7) a positive torque leads to the swash plate swiveling out. Therefore the pressure distribution at the outer dead center has a significant impact on the torque load because it is the greatest decreasingly acting torque. The two commutation elements show a different pressure rise in the piston chamber and therefore an altered torque load as well. The bore leads to a smoother pressure transition when getting connected to the high pressure kidney with the full area.

Fig. 6 shows the entire torque load of all pistons on the swash plate.
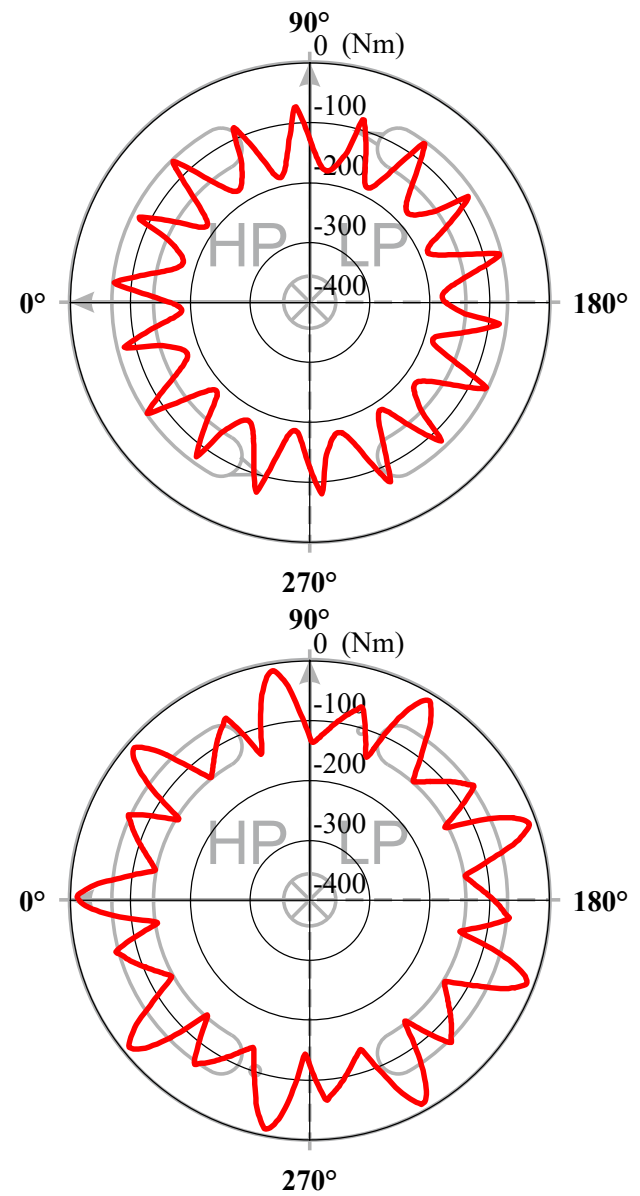

Fig.6 Torque load during one revolution (above VP2, bottom VP3)

The calculation already shows a difference between the two valve plate designs. For VP 3 the difference between the peaks results from the unequal size of the bores for compression and decompression. This is done to lengthen the angle of high pressure in the piston chamber for a counter torque on the swash plate, as shown in Fig. 5, showing the possibility of adapting the design of a valve plate according to the means of a desired torque load. For example, the amplitude of the torque load could be reduced in order to minimize the excitation of the swash plate.

\section{Swash Plate Movement}

For a controlled pump the torque load is balanced with the control force of the actuator and other damping forces. A variation of the torque load leads to a movement of the swash plate. The control actuator is moved by the swash plate and therefore the chamber volume in the control actuator is changed. This causes a pressure variation which then acts as the control actuator force on the swash plate balancing the torque load. Therefore the swash plate needs to move in order to enable pressure built up in the control actuator. The 
oscillation of the swash plate angle for the two valve plate designs with commutation elements are shown in Fig. 7.

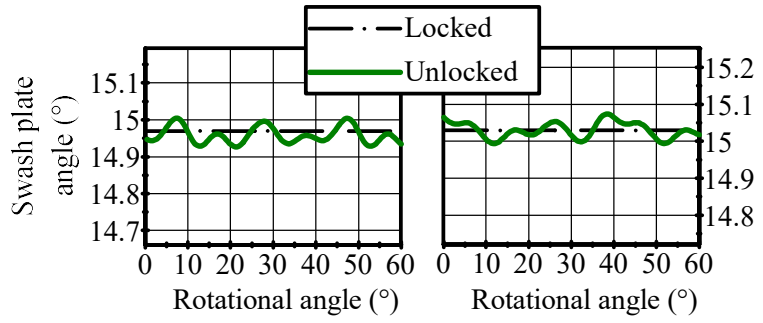

Fig.7 Swash plate angle (left: VP 2, right: VP 3)

The amplitude of the oscillation is smaller than $0.1^{\circ}$ and the curve for both valve plates do not differ significantly. The simulation is calculated without damping of the swash plate. Therefore the diagram shows the highest possible amplitude.

Achten et $\mathrm{al}^{1)}$. and Ericson ${ }^{2)}$ stated a variation of the piston stroke especially in the dead centers. For this study, the piston stroke and the piston pressure during commutation is shown in Fig. 8 for VP 2.
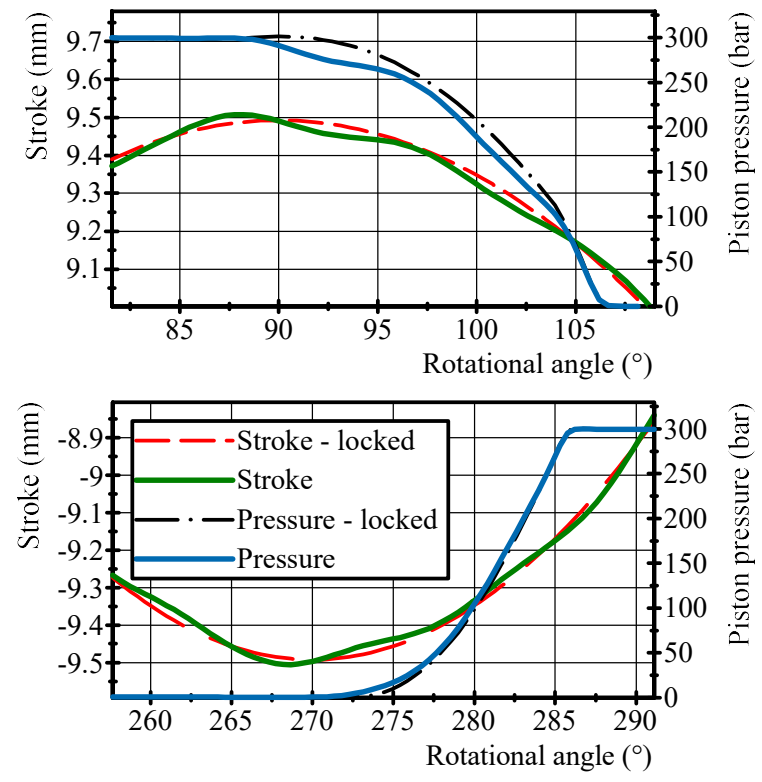

Fig.8 Swash plate movement for piston one, VP 2

(above: inner dead center, bottom: outer dead center)

The dashed lines display the stroke and pressure for a mechanically locked swash plate, for example in a constant displacement pump. For study of the swash plate oscillations this is equivalent to an ideal operation of the pump. The piston stroke is altered by the swash plate movement. This causes a change of piston pressure in two ways. On the one hand, the stroke variation alters the chamber displacement and therefore the piston pressure. On the other hand, the piston volume flow is changed by the altered piston velocity. Therefore the piston pressure gradient changes due to the altered flow through the commutation elements. At the inner dead center (on the left) the pressure gradient is significantly altered. According to
Fig. 6 this reduces the torque load in decreasing direction of the swash plate angle.

\section{Further Impact and Effects}

The torque load and resulting swash plate movement needs to be damped in order to stabilize the system. Because the torque is a force excitation on the swash plate, the realization of compensation via the force of the control actuator is rather complicated. In this case the pump controller would have to provide the pressure to the actuator at the exact time once the torque load occurs. Therefore the damping is realized mechanically by friction forces. The friction occurs in the swash plate bearing. Fig. 9 shows the calculated torque load with moderate damping for VP 2 (swash plate bearing: $\mu=0.01$, viscous friction: $\left.d_{\mathrm{SP}}=10 \mathrm{Nm} \cdot \mathrm{s}\right)$.

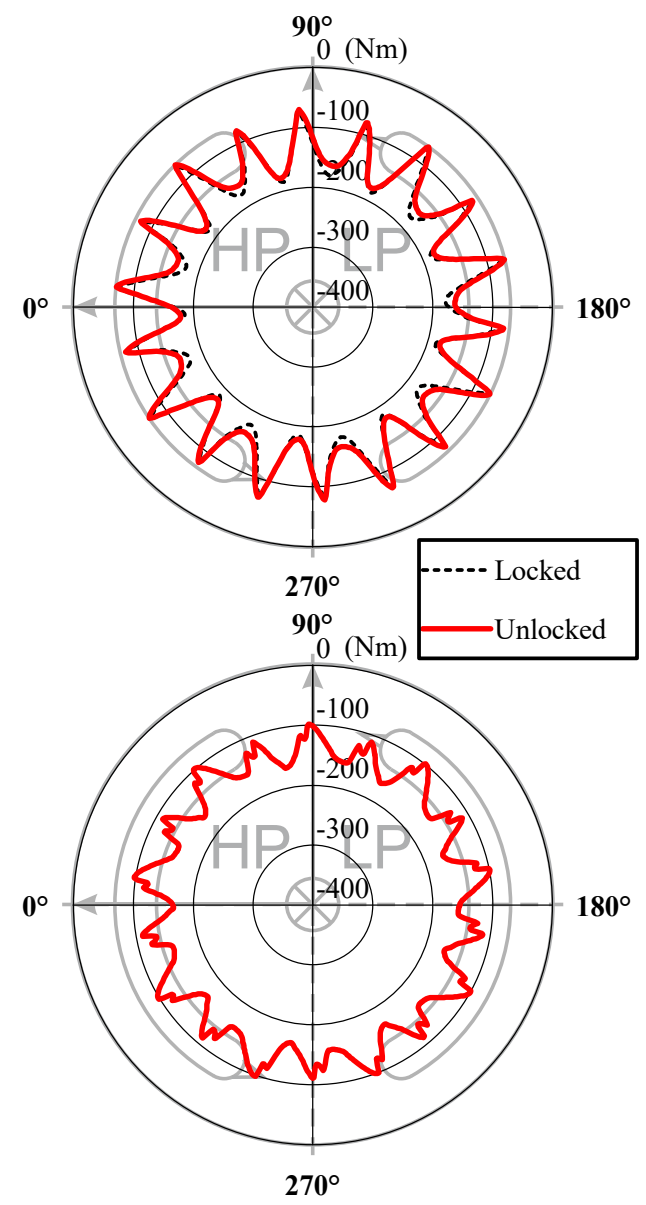

Fig.9 Torque load, VP2 (above: without damping, bottom: with moderate damping)

The damping reduces the resulting torque load. Within the simulation a preferred value can be chosen but the damping also reduces the dynamic behavior of the pump system. So there is a conflict between a well damped, stabilized system and a high dynamic system which is needed for pressure compensation or flow control. 
Ericson ${ }^{2)}$ states that the swash plate movement only minor affects the output volume flow of the pump. In order to prove this, the resulting flow at the high pressure output as a sum of all pistons' volume flows is shown in Fig. 10.
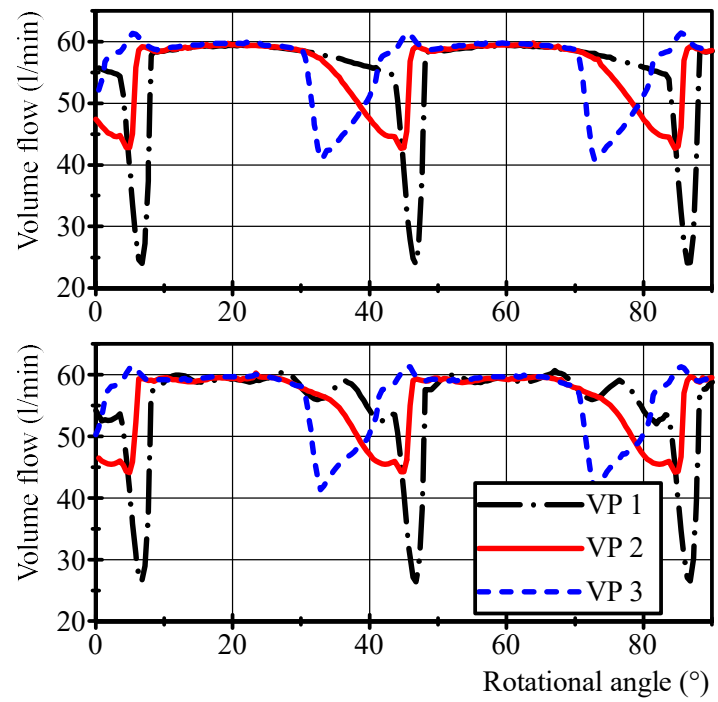

Fig.10 Volume flow (above: locked,

bottom: unlocked swash plate)

For VP 1 a pulsation of the pump's output flow for a locked swash plate occurs. Because the valve plate is not equipped with commutation elements, a high backward-flow from the high pressure port into the piston chamber results. The backward-flow then leads to a drop in the pump's output flow which is shown in Fig. 10. This drop is reduced if the swash plate is unlocked. Furthermore the swash plate movement changes the output flow remarkably.

The curves VP 2 and VP 3 show a difference in the output flow during commutation because of the different commutation area opening. The behavior is almost vice versa. The output flow of VP 2 and VP 3 is only slightly affected by the swash plate movement. Regarding the results of three valve plate, the impact of the swash plate movement of the pump's output flow strongly depends on the valve plate design.

\section{Conclusion}

State of the art swash plate pumps operated with pump controllers show a different operating condition once the swash plate is not mechanically locked in its position. The torque load of the piston pressure forces is balanced with the control actuator force. The resulting movement of the swash plate eventually changes the sinusoidal stroke of the pistons and therefore the piston pressure gradient during commutation. This concludes that the intended design of the commutation behavior is altered once the pump works in controlled operation.

The torque load on the swash plate depends on the geometry and also on the piston pressure gradient during commutation. Silencing grooves and bores alter the pressure gradient differently which has a strong effect on the resulting torque load. The torque load needs to be compensated mechanically in order to reduce the swash plate movement. This also reduces the dynamics of the pump in controlled operation. The valve plate should be designed according to the usage of the pump. A constant displacement pump should be optimized for pulsation of output flow, but for a variable displacement pump the valve plate should be designed according to the control of the pump system. Especially for a displacement controller, the torque load does have a major impact on the function. Eventually, the study shows that there is still a high potential for further investigation into the design of valve plates for variable displacement pumps.

\section{References}

1) Achten, P., Eggenkamp, S., Potma, H. W.: Swash plate oscillation in a variable displacement floating cup pump, Proceedings of the 13th Scandinavian International Conference on Fluid Power, Linköping, Sweden, p. 163176 (2013)

2) Ericson, L.: Swash Plate Oscillations due to Piston Forces in Variable In-line Pumps, 9th International Fluid Power Conference, Conference Proceedings, Aachen, p. 216-224 (2014)

3) Manring; N. D., Johnson, R. E.: Modeling and Designing a Variable-Displacement Open-Loop Pump, Journal of Dynamic Systems, Measurement, and Control 2, p. 267 271 (1996)

4) Manring, N. D.: The Control and Containment Forces on the Swash Plate of an Axial-Piston Pump, Journal of Dynamic Systems, Measurement, and Control 4, p. 599605 (1999)

5) Mandal, N. P., et al.: Pressure Compensator Design for a Swash Plate Axial Piston Pump, Journal of Dynamic Systems, Measurement, and Control 2 (2013)136(2):021001-021001-12

6) Lux, J., Murrenhoff, H.: Experimental loss analysis of displacement controlled pumps, 10th International Fluid Power Conference, Conference Proceedings, Dresden, p. 441-452 (2016) 